\title{
Lipid-lowering and anti-thrombotic therapy in patients with peripheral arterial disease
}

\section{European Atherosclerosis Society/European Society of Vascular Medicine Joint Statement}

\author{
Jill J. F. Belch ${ }^{1}$ (D), Marianne Brodmann², Iris Baumgartner ${ }^{3}$, Christoph J. Binder ${ }^{4}$, \\ Manuela Casula ${ }^{5,6}$, Christian Heiss ${ }^{7,8}$, Thomas Kahan ${ }^{9}$, Paolo Parini ${ }^{10}$, Pavel Poredos ${ }^{11}$, \\ Alberico L. Catapano6,12,*, and Lale Tokgözoğlu ${ }^{13, *}$

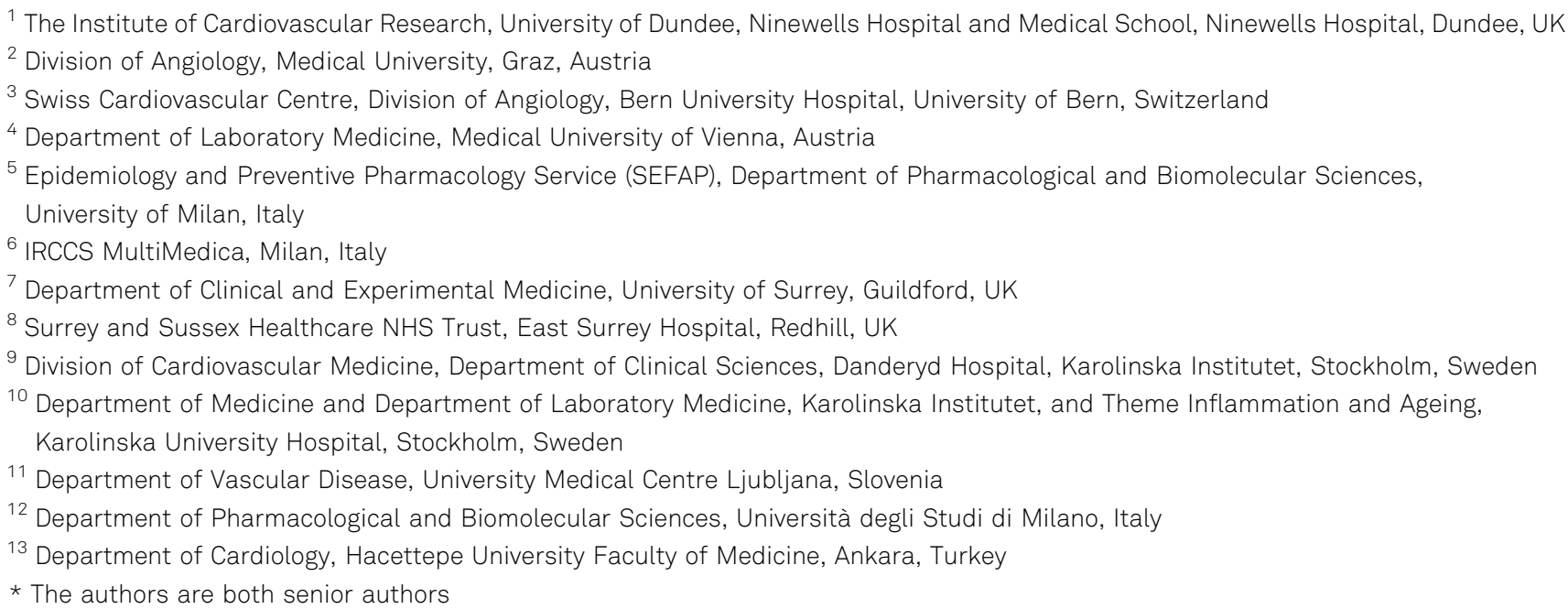

Summary: Patients with peripheral arterial disease (PAD) are at very high risk of cardiovascular events, but risk factor management is usually suboptimal. This Joint Task Force from the European Atherosclerosis Society and the European Society of Vascular Medicine has updated evidence on the management on dyslipidaemia and thrombotic factors in patients with PAD. Guidelines recommend a low-density lipoprotein cholesterol (LDLC) goal of more than $50 \%$ reduction from baseline and $<1.4 \mathrm{mmol} / \mathrm{L}(<55 \mathrm{mg} / \mathrm{dL})$ in PAD patients. As demonstrated by randomized controlled trials, lowering LDL-C not only reduces cardiovascular events but also major adverse limb events (MALE), including amputations, of the order of $25 \%$. Addition of ezetimibe or a PCSK9 inhibitor further decreases the risk of cardiovascular events, and PCSK9 inhibition has also been associated with reduction in the risk of MALE by up to $40 \%$. Furthermore, statin- based treatment improved walking performance, including maximum walking distance, and pain-free walking distance and duration. This Task Force recommends strategies for managing statin-associated muscle symptoms to ensure that PAD patients benefit from lipidlowering therapy. Antiplatelet therapy, either daily clopidogrel $75 \mathrm{mg}$ or the combination of aspirin $100 \mathrm{mg}$ and rivaroxaban $(2 \times 2.5 \mathrm{mg})$ is also indicated to prevent cardiovascular events. Dual pathway inhibition (aspirin and rivaroxaban) may be considered following revascularization, taking into account bleeding risk. This Joint Task Force believes that adherence with these recommendations for lipid-lowering and antithrombotic therapy will improve the morbidity and mortality in patients with PAD.

Keywords: Peripheral arterial disease, lipid lowering, treatment targets 


\section{Introduction}

Peripheral arterial disease (PAD), characterised by atherosclerosis in the arteries of the lower limb, poses an increasing health and societal burden world-wide. Already affecting more than $20 \%$ of individuals aged over 60 years [1 2], the prevalence will escalate as the population ages. This is highly relevant given that cardiovascular risk is higher among PAD patients than those with coronary artery disease (CAD) alone and increases with disease severity (Figure 1) [3, 4, 5]. Five-year mortality with PAD is almost double that of CAD (25\% versus $13 \%$ ) and higher than for many cancers, equating almost exactly to Duke's stage B carcinoma of colon $[3,6,7]$. Despite recognition of this high attrition rate, however, mortality associated with PAD has essentially remained unchanged over the past 25 years (Figure 2) [3, 8], unlike the decline evident for CAD $[3,9,10]$. This poor prognosis can be largely attributed to sub-optimal management of cardiovascular risk factors [9], as recommended by evidence-based guidelines $[11,12,13]$.

Although PAD and CAD are both caused by atherosclerosis and share common lesion features, the clinical course, therapeutic response and certain demographic features suggest that there are factors that make PAD subjects more susceptible to the clinical manifestations of atherosclerosis [14]. PAD is characterised by higher levels of systemic inflammation markers, and a higher prevalence of diabetes than CAD [15]. As for all phenotypes of atherosclerosis, dyslipidaemia is one of the most important modifiable cardiovascular risk factors in PAD [16].

The European Society of Vascular Medicine (ESVM) and the European Atherosclerosis Society (EAS) recognise the need for a renewed focus on the management of PAD. This Joint Statement provides clear and updated evidence-based consensus on the management on dyslipidaemia and thrombotic factors, with the aim of decreasing the appalling cardiovascular morbidity and mortality associated with PAD.

\section{Lipid-lowering therapies in PAD}

\section{What is the evidence that elevated lipids and lipoproteins increase risk for PAD?}

Despite controversy over the years, elevated lipids are now known to be associated with increased cardiovascular risk in PAD [16]. Indeed, in a previous report, a discordant lipid profile was reported in patients with PAD compared to unaffected controls [17]. As with all phenotypes of atherosclerosis, apolipoprotein (apo)B-containing lipoproteins, which include all lipoproteins except high-density lipoproteins (HDL), are key players driving the initiation and progression of disease [18]. The archetypal apoB-containing lipoprotein is low-density lipoprotein (LDL), which is established as causal for atherosclerotic cardiovascular disease (ASCVD)
$[19,20]$. There is also accumulating evidence to suggest a causal role for triglyceride-rich lipoproteins and their remnant particles in atherosclerosis [21].

ApoB-containing lipoproteins retained in the arterial wall initiate the atherosclerotic process [18]. Higher levels of apoB-containing lipoproteins in plasma promote the development and progression of atherosclerotic plaques. Hence, the concentration and total duration exposure of apoB-containing lipoproteins, together with the concentration of circulating LDL cholesterol (LDL-C), represent the overall atherosclerotic plaque burden of an individual person [22, 23].

An increased ratio of apoB/apoAI (the apolipoprotein in HDL) was predictive of PAD risk in middle aged healthy men [24]. Genetic and epidemiologic studies provide insights into the role of specific apoB-containing lipoproteins that determine this risk. A genome-wide association study including over 30,000 PAD patients and 210,000 controls of the Million Veteran Program (MVP) identified variants in the genes encoding the LDL receptor $(L D L R)$, lipoprotein lipase (LPL), and lipoprotein(a) [Lp(a)] (LPA) as drivers of $\mathrm{PAD}$ [25]. Interestingly, in replication analyses in more than 5,000 PAD patients from the UK Biobank, the $L P A$ variant was the top locus associated with PAD. This finding is supported by an epidemiologic study showing a dose-dependent association of $\mathrm{Lp}(\mathrm{a})$ molar concentration and PAD [26].

The MVP study also identified several variants that were associated with either hypercholesterolaemia or hypertriglyceridaemia and PAD [25]. These findings are important as epidemiologic support for an association between elevated LDL-C concentration and PAD is less consistent than for CAD. For example, in the Health Professionals Follow-up Study, hypercholesterolaemia contributed 17\% of the PAD risk [27]. Furthermore, associations of total cholesterol levels, total cholesterol/HDL ratio, and triglyceride concentration with PAD were often attenuated or abrogated after multivariate adjustment [28]. More recently, a prospective study of more than 27,000 women without incident PAD found that elevated LDL-particle number (based on nuclear magnetic resonance measurement) and triglyceride-rich lipoproteins but not LDL-C concentration were associated with PAD risk [29].

While some uncertainties persist regarding the contribution of individual apoB-containing lipoproteins to the different clinical manifestations of atherosclerosis, particularly in symptomatic PAD, overwhelming evidence supports the collective role of these lipoproteins in driving PAD. Moreover, as LDL-C is unequivocally established as causal for ASCVD [19], it is therefore the primary target when treating dyslipidaemia in patients with PAD [30].

\section{What are the lipid goals in PAD?}

The 2019 European Society of Cardiology/EAS dyslipidaemia guidelines recommend LDL-C goals according to the 10-year risk for fatal cardiovascular events. Patients with PAD belong in the very high-risk category, with 


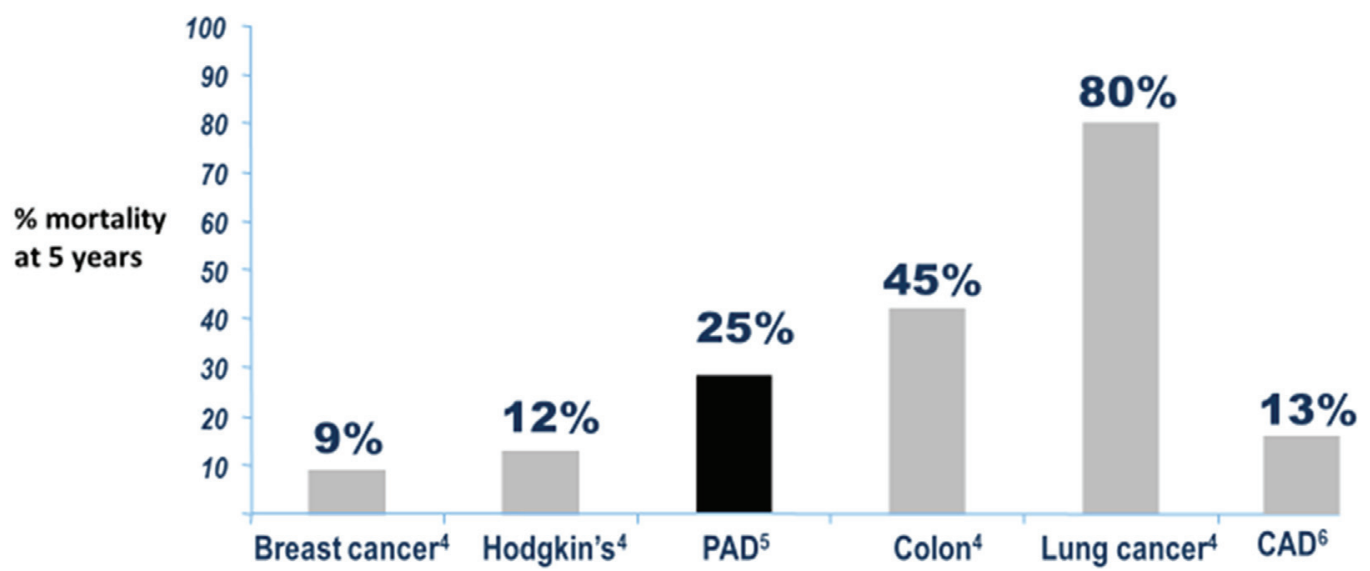

“American Cancer Society. Cancer Facts and Figures - hittps://www.cancer.org/content/dam/cancer-org/research/cancer-facts-and-statistics/annual-cancer-facts-and-figures/2018/cancer-factsEOLE prospective cohort study. Long-term survival after MI. https://doi.org/10.1016/j.therap.2019.02.001

Figure 1. Comparison of 5-year mortality rates: PAD versus common cancers.

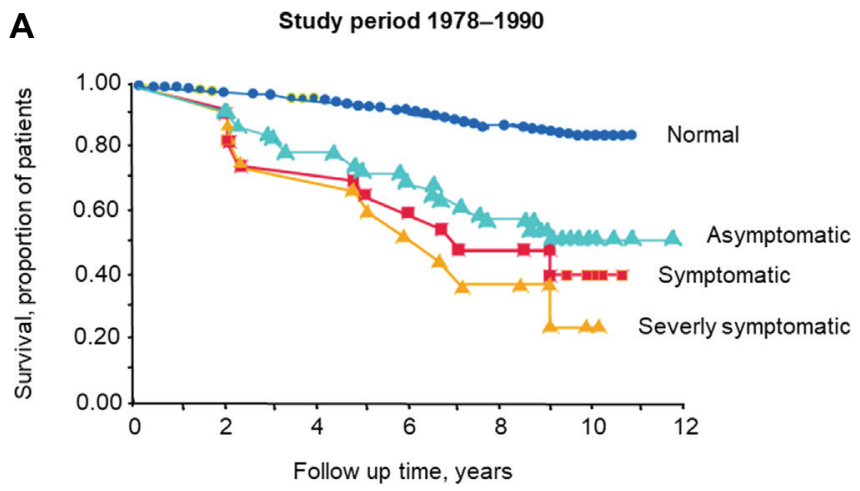

B

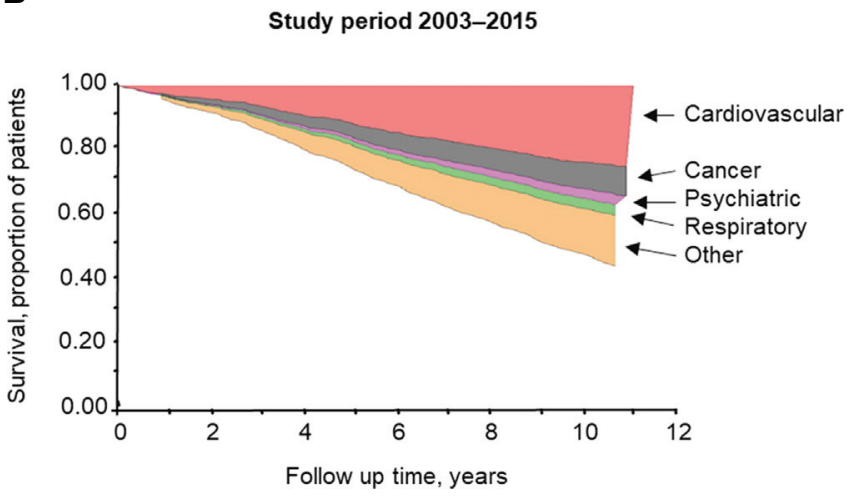

Figure 2. Little change in PAD patient survival over the last 25 years. Comparison of 10-year survival (A) between 1978 and 1990 (modified from Criqui et al. [10]) and (B) between 2003 and 2015 (according to cause of death) (modified from Sartipy et al. [3]).

$\geq 10 \%$ risk of a fatal cardiovascular event. In these patients, both LDL-C reduction by $\geq 50 \%$ from baseline and an LDL-C goal of $<1.4 \mathrm{mmol} / \mathrm{L}(<55 \mathrm{mg} / \mathrm{dL})$ are recommended [30].

To attain this LDL-C goal treatment with a high-intensity statin at the maximal tolerated dose is recommended. If patients are unable to attain goal or report statin intolerance, a combination of statin (at a lower dose if statin intolerant) with ezetimibe is recommended, with addition of a
PCSK9 (proprotein convertase subtilisin/kexin type 9) inhibitor if further LDL-C lowering is indicated [31]. Lipid levels should be monitored $8( \pm 4)$ weeks after starting or adjusting treatment until LDL-C goal is achieved, and thereafter at least annually or as indicated.

Despite guideline recommendations, however, PAD patients are often underdiagnosed and inadequately managed compared with CAD patients, both for lifestyle intervention and pharmacotherapy [32]. As with other very 
Table I. Effect of statin treatment on cardiovascular and major adverse limb events in patients with peripheral arterial disease

\begin{tabular}{lcc}
\hline Outcome & Relative risk reduction (\%) & Hazard ratio (95\% Cl) \\
\hline Composite cardiovascular events & 34 & $0.662(0.59-0.741)$ \\
Cardiovascular death & 41 & $0.594(0.455-0.777)$ \\
All-cause death & 39 & $0.608(0.543-0.680)$ \\
Major adverse limb events & 30 & $0.702(0.605-0.815)$ \\
Amputation & 35 & $0.654(0.522-0.819)$ \\
\hline
\end{tabular}

Results from a meta-analysis of 51 studies in 138,060 patients, 35\% treated with a statin. Derived from Pastori et al. [39].

high-risk groups, registries show disappointing results in terms of adherence with lifestyle and LDL-C goal achievement. In a study of symptomatic PAD patients, less than three-quarters did not attain an LDL-C level below 1.8 $\mathrm{mmol} / \mathrm{L}(70 \mathrm{mg} / \mathrm{dL})$ and nearly half had LDL-C levels above $2.5 \mathrm{mmol} / \mathrm{L}$ (100 mg/dL) [33]. Similar findings were reported among PAD patients included in studies of high cardiovascular risk populations $[34,35]$.

\section{What is the evidence that lipid-lowering therapy improves outcome in PAD?}

While lipid-lowering therapy indisputably reduces cardiovascular events in patients with CAD, evidence from prospective well-powered studies in PAD patients is more limited. In a systematic review of 18 trials of different lipid-lowering agents in 10,000 patients with lower limb PAD, lowering LDL-C concentration was associated with $20 \%$ reduction in total cardiovascular events and improvements in total walking distance and pain-free walking distance, but not ankle brachial index (ABI) [36]. Evidence for individual lipid-lowering therapies is summarized below.

\section{Statins}

Statins are guideline-recommended first line lipid-lowering therapy in patients with PAD, supported by definitive evidence of cardiovascular morbidity and mortality benefits $[12,37,38]$. Furthermore, there is also support for positive effects of lipid-lowering on major adverse limb events (MALE), as well as walking performance in patients with PAD.

\section{Major adverse cardiovascular events (MACE) and MALE}

There is clear evidence that statin treatment substantially improves cardiovascular outcomes and MALE in PAD patients. One meta-analysis evaluated 51 studies ( 2 randomized controlled trials, 20 prospective studies, and 29 retrospective studies) in 138,060 PAD patients with either stable claudication, critical limb ischaemia (CLI) or undergoing lower extremity revascularization, of whom 35\% received a statin [39]. MACE included all-cause death, composite cardiovascular endpoints, cardiovascular death and stroke, and MALE included amputation and graft occlusion/revascularization. Statin treatment not only reduced all-cause mortality by $39 \%$, cardiovascular death by $41 \%$, cardiovascular outcomes by $34 \%$ and ischaemic stroke by $28 \%$, but also reduced MALE by $30 \%$ and amputations by $35 \%$ (Table I). Another meta-analysis of 19 studies in 26,985 patients with CLI, about half on a statin, showed $25 \%$ reduction in amputation and $38 \%$ reduction in fatal events. Statin therapy was also associated with improved overall patency rates and lower incidence of MACE [40].

To some extent findings from these meta-analyses are confounded by inclusion of retrospective studies, as well as the fact that generally less than half of these patients were on a statin. To address these issues, this Joint Task Force conducted a meta-analysis of randomized controlled trials of statin-based treatment identified by MEDLINE searches which reported major cardiovascular events, cardiovascular mortality, or all-cause mortality in PAD patients [41, 42, 43, 44, 45]. Estimates for between group differences (statin vs. control) were derived using both fixed-effects (Mantel \& Haenszel method) [46] and random-effects models (DerSimonian \& Laird method) [47], with the latter reported if there was significant heterogeneity. Overall, this analysis showed that statin treatment reduced MACE by $24 \%$ (odds ratio $0.76,95 \%$ confidence interval [CI] 0.69-0.83), cardiovascular death by $17 \%$ (odds ratio 0.83, 95\% CI: 0.26-2.60) and all-cause mortality by $18 \%$ (odds ratio 0.82 , 95\% CI: 0.69-0.97) (Figure 3).

\section{Outcome after limb intervention}

There are limited data for the effect of statin treatment on outcomes after surgical and endovascular procedures. Pooled analysis of seven studies in patients with CLI, did, however, indicate that statin treatment was associated with lower rates of loss of patency (hazard ratio: 0.80, 95\% CI: 0.66-0.96) [40].

\section{Claudication development}

There is some evidence that statin treatment can decrease the development and progression of PAD. For example, analyses from the Scandinavian Simvastatin Survival Study (4S), showed that cholesterol lowering with simvastatin reduced the incidence of carotid bruits and cerebrovascular events, as well as new-onset or worsening of angina pectoris and intermittent claudication [48]. The authors concluded that simvastatin may have a general anti-atherosclerotic effect not limited to the coronary bed. More recently, investigation of atheroma burden using serial whole body magnetic resonance angiography over 3 years showed that individuals with atheroma progression at 
A

\begin{tabular}{|c|c|c|c|c|c|}
\hline & Statins & & Control & & \\
\hline Study & Events & $\mathbf{N}$ & Events & $\mathbf{N}$ & OR \\
\hline Castaño 2003 [41] & 1 & 14 & 0 & 14 & 3.24 \\
\hline Mohler 2003 [42] & 12 & 240 & 12 & 214 & 0.89 \\
\hline Heart Protection Study 2007 [43] & 895 & 3384 & 1101 & 3364 & 0.74 \\
\hline Ramos 2016 [44] & 201 & 2728 & 245 & 2721 & 0.80 \\
\hline $\begin{array}{l}\text { Summary } \\
\text { Test for heterogeneity }\end{array}$ & 1109 & $\begin{array}{r}6366 \\
p=0.69\end{array}$ & 1358 & $\begin{array}{l}6313 \\
(0.69\end{array}$ & $\begin{array}{r}0.7 \\
0.8\end{array}$ \\
\hline
\end{tabular}

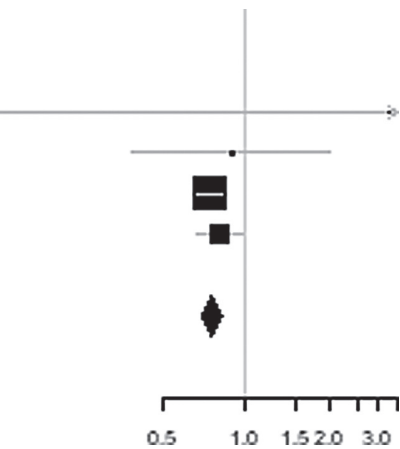

B

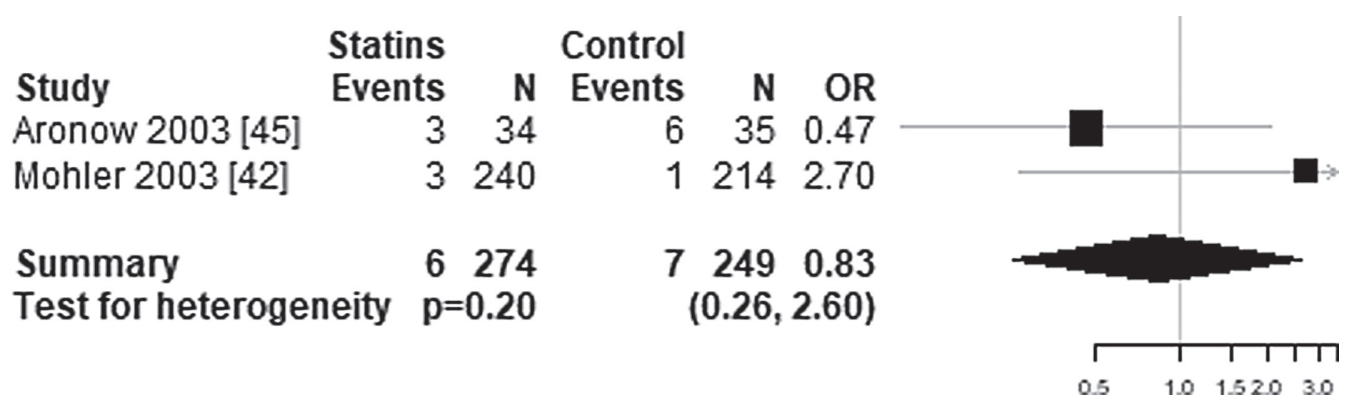

C

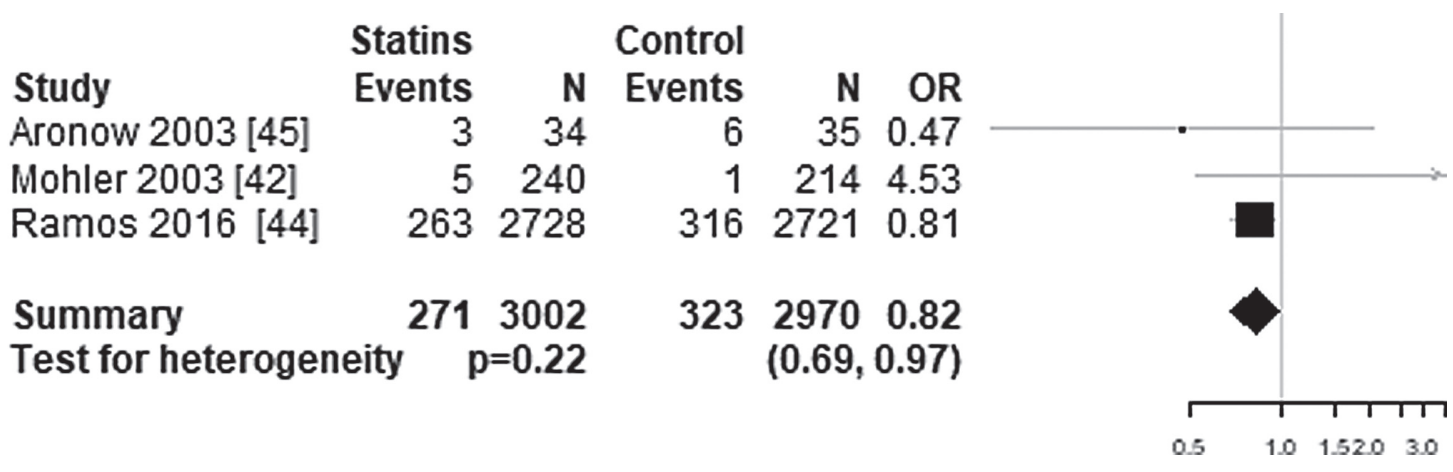

Figure 3. Effect of statin-based treatment on the risk of cardiovascular outcomes and all-cause mortality in patients with PAD. Meta-analysis of randomized controlled trials of statin therapy, showing the effects of statin-based treatment on risk for MACE (A), cardiovascular death (B) and all-cause mortality (C). Analyses based on data in Castano et al. [41], Mohler et al. [42], Heart Protection Study Collaborative Group et al. [43], Ramos et al. [44] and Aronow et al. [45]. (A) Effect of statin-based treatment on risk for MACE. (B) Effect of statin-based treatment on risk of cardiovascular death. (C) Effect of statin-based treatment on risk of all-cause mortality.

follow-up were less likely to be on statin therapy (79\% vs. $100 \%, \mathrm{p}=0.04)$, and had a significantly higher baseline atheroma score $(17.6 \pm 11.2$ vs. $10.7 \pm 5.1, \mathrm{p}=0.043)$ [49].

\section{Walking performance}

Statin treatment was also shown to favourably impact walking performance in PAD patients with claudication. In one meta-analysis, maximal walking distance for patients on lipid-lowering therapy, notably statins, improved more than that reported with vasodilators, phosphodiesterase and platelet inhibitors (increase by 150 vs. 50 metres) [50]. This benefit increased over time with maximal effect after several months of treatment but was not accompanied by improvement in ABI measurement. Another study showed no difference between patients with claudication doing exercise training treated with atorvastatin versus control, suggesting no added benefit from statin treatment [51].

The effects of statin-based treatment on walking performance were further investigated in the meta-analysis conducted by this Joint Task Force [41, 42, 45, 51, 52]. Two outcomes were evaluated: maximal walking distance and free-pain walking (both duration and distance) on a treadmill. Based on the random-effects model, statin treatment improved walking distance by 45 metres (95\% CI: -64.7 to 154.7 metres). There was also improvement in pain-free walking distance and duration (by 15.3 metres [95\% CI: -6.8 to 87.5 ] and 54.9 seconds [95\% CI: $40.4-$ 69.3], respectively). 


\section{Combination treatment with statin and ezetimibe}

Guidelines recommend the addition of ezetimibe if very high-risk patients fail to attain LDL-C goal with maximally tolerated statin therapy. The cardiovascular benefits of this combination therapy is supported by results from IMPROVE-IT (IMProved Reduction of Outcomes:Vytorin Efficacy International Trial), in which ezetimibe on top of simvastatin therapy significantly reduced cardiovascular events (a composite of cardiovascular death, myocardial infarction, unstable angina requiring rehospitalization, coronary revascularization or non-fatal stroke) in patients with ACS (hazard ratio: 0.936; 95\% CI: 0.89-0.99; $\mathrm{p}=0.016$ ) [53]. Subgroup analyses investigated the effects of this combination treatment in patients with polyvascular disease; 1005 (6\%) had PAD and 1071 (6\%) had stroke or transient ischaemic attack at baseline, with concomitant type 2 diabetes in over one-third [54]. Patients with polyvascular disease were at higher risk, with 7-year Kaplan-Meier cardiovascular event rates $39.8 \%$ and $60.0 \%$ with concomitant type 2 diabetes versus $29.6 \%$ in those with ACS alone.

Although the relative risk reduction associated with ezetimibe plus simvastatin was consistent in patients with or without concomitant polyvascular disease, the absolute benefit was substantially higher in patients with polyvascular disease, especially those with concomitant type 2 diabetes (absolute risk reductions $4.2 \%$ and $9.1 \%$ vs. $1.7 \%$ in those with ACS alone). These translated to a number needed to treat to prevent one event of 24 in patients with polyvascular disease and 11 with concomitant type 2 diabetes versus 59 in those with ACS alone [54]. These findings reinforce the greater cardiovascular benefit from further LDL-C lowering with the combination of ezetimibe and simvastatin.

\section{Combination treatment with statin and a PCSK9 inhibitor}

Monoclonal antibodies against PCSK9, i.e., evolocumab and alirocumab, are highly efficacious treatments that reduce LDL-C by $60 \%$ on top of statin therapy and are associated with significant reduction in cardiovascular events in outcomes studies in very high-risk populations $[55,56]$. Prespecified analyses of these trials have also demonstrated cardiovascular and limb benefit in PAD patients.

\section{What is the evidence that PCSK9 inhibitors, on top of statins, improve outcome in PAD patients?}

The FOURIER trial (Further Cardiovascular Outcomes Research with PCSK9 Inhibition in Subjects with Elevated Risk) trial investigated treatment with evolocumab against a background of intense statin therapy (with or without ezetimibe) in 27,564 patients with coronary, cerebrovascular, or peripheral arterial atherosclerosis [55]. A prespecified analysis included 3,642 patients with confirmed lower limb
$\mathrm{PAD}$, identified by intermittent claudication and an $\mathrm{ABI}$ $<0.85$, or with a prior peripheral vascular procedure [57]. At the time of randomization, $57 \%$ of patients had a history of peripheral revascularization, $3 \%$ had undergone amputation, and $69 \%$ had an $\mathrm{ABI}<0.85$ and claudication. Almost all were on a statin and $89 \%$ were also on antiplatelet therapy. These patients were at higher absolute risk of both MACE and MALE when compared with those with atherosclerosis affecting other vascular beds. Treatment with evolocumab significantly reduced the primary end point (a composite of cardiovascular death, myocardial infarction, stroke, hospitalization for unstable angina, or coronary revascularization) by $21 \%$, as well as the risk of MALE by $42 \%$ [57]. Thus, FOURIER was the first randomized trial to demonstrate that intensive LDL-C lowering decreases the risk of MALE with no safety concerns.

Subsequent analyses of the ODYSSEY OUTCOMES study in 18,924 patients with recent acute coronary syndrome provides further insights [56]. Patients were randomized to alirocumab on top of maximally tolerated statin or statin alone. In those patients who also had PAD (3.2\% of the total study population), treatment with alirocumab was associated with $7 \%$ reduction in relative risk for the primary endpoint (a composite of coronary heart disease death, nonfatal myocardial infarction, fatal or nonfatal ischaemic stroke, or unstable angina requiring hospitalization) [58]. In patients with atherosclerosis in three vascular territories, the relative risk reduction was substantially higher (by 36\% versus $15 \%$ for the overall study population) [58]. In a subsequent analysis including all patients with a history of PAD, treatment with alirocumab significantly reduced the risk for PAD events (a composite of critical limb ischaemia, limb revascularization, and amputation for ischaemia) by $41 \%$, corresponding to an $8.6 \%$ absolute reduction in risk at 3 years. Notably, the ODYSSEY OUTCOMES Study Investigators identified baseline $\mathrm{Lp}$ (a) but not LDL-C concentration as a predictor of the reduction in risk for PAD events with alirocumab [59].

Finally, combined analysis of both trials conducted by this Joint Task Force showed that treatment with a PCSK9 inhibitor, on top of maximally tolerated statin therapy, was associated with a significant $24 \%$ reduction in cardiovascular events (odds ratio 0.76, 95\% CI: 0.64-0.91), although the difference in all-cause mortality did not achieve statistical significance (odds ratio 0.85, 95\% CI: 0.671.09) $[57,58]$.

\section{How to manage muscle adverse effects with statins}

Beyond efficacy, the adverse effects of statin therapy, notably perceived or reported muscle pain and cramping, merit consideration in the setting of PAD, given their potential detrimental impact on treatment compliance. Statin associated muscle symptoms (often referred to as SAMS) cover a broad range of clinical presentations, including pain or itching, stiffness, tenderness or cramping, 
and may affect about $15-20 \%$ of patients, more frequently women than men $[60,61]$. Clinical presentation of muscle symptoms is highly heterogenous, although muscle pain and weakness are usually symmetrical and proximal and affect large muscle groups including the thigh, buttock, calves, and back muscles, typically occurring 4-6 weeks after starting treatment [62]. The risk of muscle pain with statins is increased in patients aged over 80 years, as well as those with a smaller body frame, excessive alcohol intake, or hypothyroidism. The onset of new symptoms may occur with an increase in statin dose or after initiation of an interacting drug [63]. People who have exercised regularly before taking statins are less likely to experience muscle pain.

The underlying mechanisms of muscle pain in statin users are not completely elucidated. Preclinical studies showed that statins decrease mitochondrial function, attenuate energy production and alter muscle protein degradation. Additionally, statins cause spontaneous and irregular leaks of calcium from storage within muscle cells and provoke muscle contraction; unregulated calcium leak may also cause damage to muscle cells leading to muscle pain and weakness [64].

SAMS significantly contribute to very high discontinuation rates of statin therapy (up to 75\%) [65]. Anecdotally, this proportionally affects many patients with PAD who already have muscle problems in the legs. Treatment non-adherence may have a marked impact on the cardiovascular benefits of statin treatment. In one meta-analysis, patients who were adherent to statin treatment had a $15 \%$ lower risk of cardiovascular events compared with those with low adherence [66]. To overcome SAMS, the use of an alternative statin which is metabolised via different hepatic cytochromes is generally recommended, for example the use of rosuvastatin instead of atorvastatin or simvastatin or vice versa.

SAMS are manageable; studies indicate that $90 \%$ of patients reporting muscle symptoms are able to tolerate an alternative statin [67]. Another recommended approach is the combination of the maximally tolerated statin dose and a non-statin lipid-lowering therapy such as ezetimibe to attain LDL-C goal.

\section{Conclusions}

Taken together, the available literature shows that patients with PAD are at very high cardiovascular risk and should be targeted to achieve guideline-recommended LDL-C goal. Statin-based treatment has been shown to substantially reduce the risk of MACE and MALE by about 25\%. The addition of a PCSK9 inhibitor further decreases this risk. Statin-based treatment has also been associated with improved walking performance, including maximum walking distance, and pain-free walking distance and duration.

Perceived or reported muscle symptoms should be assessed and every effort made to ensure that the patients remain on lipid-lowering therapy. Recommended strategies include the use of a lower statin dose combined with a non-statin lipid-lowering therapy such as ezetimibe to attain LDL-C goal.

\section{Antithrombotic therapies in PAD}

\section{What can we learn from genetic studies?}

Patients with PAD are at high risk of MACE and MALE due to underlying atherothrombotic disease. Genetic studies provide novel insights into thrombotic factors associated with this risk. A genome-wide association study of PAD patients and controls of the MVP (discussed previously) identified a new PAD risk variant in Factor $\mathrm{V}$ (Factor $\mathrm{V}$ Leiden) that was uniquely associated with PAD, but not other vascular beds. The association of this variant with PAD risk increased with disease severity and was highest with PAD related amputation (odds ratio 1.62) [25]. Given that Factor V Leiden is the most common cause for inherited thrombophilia, this finding underlines the prominent role of thrombosis in the pathogenesis of PAD. Another study showed that CLI in PAD patients was associated with thrombotic luminal occlusion in the absence of advanced atherosclerosis [68]. Furthermore, the close functional relationship between Factor V and Factor Xa in the coagulation cascade supports preventive approaches targeting Factor $\mathrm{Xa}$, as illustrated by the COMPASS trial with the combination of low-dose rivaroxaban and aspirin versus aspirin alone [69].

\section{What is the evidence that antithrombotic therapy reduces MACE and MALE in PAD?}

Current management of symptomatic PAD includes antiplatelet monotherapy (either aspirin 75-100 mg daily or clopidogrel $75 \mathrm{mg}$ daily), with improved benefit from more intense antiplatelet therapy $[12,70,71]$. The Antithrombotic Trialist Collaboration study in 6,200 patients with intermittent claudication demonstrated significant reduction in MACE with antiplatelet therapy (most commonly aspirin) versus control (6.4\% vs. 7.9\%) [72]. A subsequent post hoc analysis of the CAPRIE trial $(n=6,452)$ showed that clopidogrel was superior to aspirin in patients with clinical PAD, with significant reductions in cardiovascular mortality (hazard ratio: 0.76, 95\% CI: 0.64-0.91) and MACE (hazard ratio: 0.78, 95\% CI: 0.65-0.93) [73]. Although a post hoc analysis of 3,906 asymptomatic and symptomatic PAD patients included in the CHARISMA trial indicated reduction in myocardial infarction with both aspirin and clopidogrel vs. aspirin monotherapy (hazard ratio: 0.63, 95\% CI: 0.42-0.95), this was also associated with a significantly increased risk of bleeding (hazard ratio: 1.99, 95\% CI: 1.69-2.34) [74].

Following below-the-knee bypass grafting, dual antiplatelet therapy (DAPT) was shown to reduce the primary efficacy endpoints (composite of index-graft occlusion or revascularization, above-ankle amputation of the affected 
Recommendation 1. Statins, at the highest tolerated dose, are indicated in patients with PAD for the prevention of cardiovascular events.

Recommendation 2. Low-density lipoprotein cholesterol (LDL-C) should be lowered to $<1.4 \mathrm{mmol} / \mathrm{L}(<55$ $\mathrm{mg} / \mathrm{dL}$ ) and by $>50 \%$ if pre-treatment values are $1.8-3.5 \mathrm{mmol} / \mathrm{l}(70-135 \mathrm{mg} / \mathrm{dL})$.

Recommendation 3. Combination treatment with a statin and ezetimibe may be considered to improve LDL-C goal attainment. This approach could allow better tolerance of a lower dose of statin in patients with statin side effects.

Recommendation 4. A PCSK9 inhibitor should be added if LDL-C levels remain $50 \%$ higher than goal despite statin treatment, with or without ezetimibe.

Recommendation 5. Antiplatelet therapy is indicated to prevent further cardiovascular events. This should be either clopidogrel $75 \mathrm{mg} /$ day, or the combination of aspirin $100 \mathrm{mg} /$ day and rivaroxaban ( $2 \mathrm{x}$ $2.5 \mathrm{mg} /$ day).

Recommendation 6. Dual antiplatelet therapy (DAPT) should be given for at least one month after drug coated balloon angioplasty, and for 3 months after either drug eluting or covered stent implantation.

Recommendation 7. Based on results from the VOYAGER study, combination therapy with aspirin (100 mg/day) and rivaroxaban $(2 \times 2.5 \mathrm{mg} /$ day $)$ should be considered for DAPT post-intervention.

Figure 4. Recommendations of the European Atherosclerosis Society/European Society of Vascular Medicine Task Force for the management of PAD patients.

limb, or death) in patients receiving a prosthetic but not venous graft [75]. In patients with stent implantation, prolonged DAPT should be considered with a recent acute coronary syndrome and/or percutaneous coronary intervention ( $<1$ year), stenting of the last patent coronary artery, and multiple coronary vessel disease in diabetes patients with incomplete revascularization. In support, the PRODIGY trial demonstrated benefit with prolonged DAPT (24 months vs. 6 months) after acute coronary syndrome only in patients with concomitant PAD (hazard ratio: 0.54, 95\% CI: 0.31-0.95) [76]. Additionally, the PEGASUS-TIMI 54 trial demonstrated that DAPT (ticagrelor plus aspirin) in stable patients with prior myocardial infarction (1-3 years) significantly reduced the risk of MALE (acute limb ischaemia and peripheral revascularization) in a subgroup of patients with PAD (hazard ratio: 0.65, 95\% CI: 0.44-0.95) [77].

While plasma coagulation is also implicated as a contributor to peripheral events, trials of therapeutic anticoagulation using vitamin $\mathrm{K}$ antagonists in PAD patients showed little benefit and caused increased bleeding. Inhibition of thrombin generation with a low dose Factor Xa inhibitor added to antiplatelet therapy can reduce ischaemic risk, as demonstrated by the COMPASS trial in patients with stable CAD or PAD $[69,78]$. The combination of rivaroxaban $2.5 \mathrm{mg}$ twice daily and aspirin $100 \mathrm{mg}$ once daily reduced the risk of MACE by $28 \%$ (hazard ratio: 0.72 ,
95\% CI: 0.57-0.90), as well as limb events, including MALE by $46 \%$ (hazard ratio: $0.54,95 \%$ CI: $0.35-0.84$ ), acute limb ischaemia by $44 \%$ (hazard ratio: $0.56,95 \%$ CI: 0.32-0.99), and MALE plus major amputation by $46 \%$ (hazard ratio: $0.54,95 \%$ CI: $0.35-0.82$ ). There was, however, an increase in major bleeding but not fatal or critical organ bleeding (hazard ratio: 1.61, 95\% CI: 1.12-2.31). Thus, the COMPASS trial demonstrated for the first time that antithrombotic treatment in patients with PAD reduces both MACE and MALE, including amputation, although at the risk of increased bleeding [79].

Finally, VOYAGER PAD compared rivaroxaban $2.5 \mathrm{mg}$ twice daily plus aspirin and aspirin alone in 6,564 PAD patients who had undergone lower-extremity revascularization [80]. The primary efficacy outcome was a composite of acute limb ischaemia, major amputation for vascular causes, myocardial infarction, ischaemic stroke or cardiovascular death. Three-year Kaplan-Meier estimates showed a significant $15 \%$ reduction in the primary outcome in the rivaroxaban group ( $17.3 \%$ vs. $19.9 \%$ with placebo, hazard ratio: $0.85,95 \%$ CI: $0.76-0.96 ; \mathrm{p}=0.009)$. The absolute risk reduction was $1.5 \%$ at 6 months, $2.0 \%$ at one year and $2.6 \%$ at 3 years. While TIMI major bleeding did not differ significantly between the groups, the incidence of ISTH (International Society on Thrombosis and Haemostasis) major bleeding was significantly higher with rivaroxaban and aspirin than with aspirin alone. It was 
estimated that for every 10,000 patients treated for one year, rivaroxaban $2.5 \mathrm{mg}$ twice daily added to aspirin would prevent 181 primary efficacy outcome events at the cost of 29 principal safety outcome events [80].

Taken together, the results from the VOYAGER PAD trial complement and extend findings from the COMPASS trial. Thus, for patients with extensive PAD, especially those who have undergone revascularization for PAD, addition of rivaroxaban to the treatment regimen may be considered weighing concomitantly the bleeding risk.

\section{Key recommendations}

Based on the evidence discussed in this statement, this Joint EAS-ESVM Task Force provides recommendations for the management of PAD patients (Figure 4). Optimal management of dyslipidaemia, together with guideline recommended antithrombotic therapy, are essential to improve the morbidity, disability and mortality of this increasingly prevalent - but underdiagnosed and undertreated - condition.

\section{References}

1. Diehm C, Schuster A, Allenberg JR, Darius H, Haberl R, Lange $\mathrm{S}$, et al. High prevalence of peripheral arterial disease and comorbidity in 6880 primary care patients: cross-sectional study. Atherosclerosis. 2004;172:95-105.

2. Fowkes FGR, Rudan D, Rudan I, Aboyans V, Denenberg JO, McDermott MM, et al. Comparison of global estimates of prevalence and risk factors for peripheral artery disease in 2000 and 2010: a systematic review and analysis. Lancet. 2013;382:1329-40.

3. Sartipy F, Sigvant B, Lundin F, Wahlberg E. Ten year mortality in different peripheral arterial disease stages: a population based observational study on outcome. Eur J Vasc Endovasc Surg. 2018:55:529-36.

4. Chen DC, Singh GD, Armstrong EJ, Waldo SW, Laird JR, Amsterdam EA. Long-term comparative outcomes of patients with peripheral artery disease with and without concomitant coronary artery disease. Am J Cardiol. 2017;119:1146-52.

5. Welten GMJM, Schouten O, Hoeks SE, Chonchol M, Vidakovic $\mathrm{R}$, van Domburg RT, et al. Long-term prognosis of patients with peripheral arterial disease: a comparison in patients with coronary artery disease. J Am Coll Cardiol. 2008;51:1588-96.

6. American Cancer Society. Cancer Facts \& Figures 2019. Atlanta: American Cancer Society; 2019. Available from https://www. cancer.org/research/cancer-facts-statistics/all-cancer-factsfigures/cancer-facts-figures-2019.html

7. Droz-Perroteau C, Blin P, Dureau-Pournin C, Thomas D, Danchin N, Tricoire J, et al. Six-year survival study after myocardial infarction: The EOLE prospective cohort study. Long-term survival after MI. Therapie. 2019;74:459-68.

8. Criqui MH, Fronek A, Barrett-Connor E, Klauber MR, Gabriel S, Goodman D. The prevalence of peripheral arterial disease in a defined population. Circulation. 1985;71:510-5.

9. Belch JJ, Topol EJ, Agnelli G, Bertrand M, Califf RM, Clement $\mathrm{DL}$, et al. Critical issues in peripheral arterial disease detection and management: a call to action. Arch Intern Med. 2003;163:884-92.

10. Criqui $\mathrm{MH}$, Langer RD, Fronek A, Feigelson HS, Klauber MR, McCann TJ, et al. Mortality over a period of 10 years in patients with peripheral arterial disease. $N$ Engl J Med. 1992;326:381-6.
11. Reinecke $H$, Unrath M, Freisinger E, Bunzemeier $H$, Meyborg M, Luders F, et al. Peripheral arterial disease and critical limb ischaemia: still poor outcomes and lack of guideline adherence. Eur Heart J. 2015;36:932-8.

12. Frank U, Nikol S, Belch J, Boc V, Brodmann M, Carpentier PH, et al. ESVM guideline on peripheral arterial disease. VASA. 2019;48:1-79.

13. Landmesser U, Chapman MJ, Stock JK, Amarenco P, Belch JJF, Borén J, et al. 2017 Update of ESC/EAS Task Force on practical clinical guidance for proprotein convertase subtilisin/kexin type 9 inhibition in patients with atherosclerotic cardiovascular disease or in familial hypercholesterolaemia. Eur Heart J. 2018;39(4):1131-43.

14. Rein P, Saely $\mathrm{CH}$, Silbernagel G, Vonbank A, Mathies R, Drexel $H$, et al. Systemic inflammation is higher in peripheral artery disease than in stable coronary artery disease. Atherosclerosis. 2015;239:299-303.

15. Silbernagel G, Rein P, Saely CH, Engelberger RP, Willenberg T, Do D-D, et al. Prevalence of type 2 diabetes is higher in peripheral artery disease than in coronary artery disease patients. Diab Vasc Dis Res. 2015;12:146-9.

16. Tunstall-Pedoe H, Peters SAE, Woodward M, Struthers AD, Belch JJF. Twenty-year predictors of peripheral arterial disease compared with coronary heart disease in the Scottish Heart Health Extended Cohort (SHHEC). J Am Heart Assoc. 2017;6.

17. Rizzo M, Pernice V, Frasheri A, Berneis K. Atherogenic lipoprotein phenotype and LDL size and subclasses in patients with peripheral arterial disease. Atherosclerosis. 2008;197:237-41.

18. Boren J, Williams KJ, The central role of arterial retention of cholesterol-rich apolipoprotein-B-containing lipoproteins in the pathogenesis of atherosclerosis: a triumph of simplicity. Curr Opin Lipidol. 2016;27:473-83.

19. Ference BA, Ginsberg HN, Graham I, Ray KK, Packard CJ, Bruckert E, et al. Low-density lipoproteins cause atherosclerotic cardiovascular disease. 1. Evidence from genetic, epidemiologic, and clinical studies. A consensus statement from the European Atherosclerosis Society Consensus Panel. Eur Heart J. 2017;38:2459-72.

20. Borén J, Chapman MJ, Krauss RM, Packard CJ, Bentzon JF, Binder CJ, et al. Low-density lipoproteins cause atherosclerotic cardiovascular disease: pathophysiological, genetic, and therapeutic insights: a consensus statement from the European Atherosclerosis Society Consensus Panel. Eur Heart J. 2020;41:2313-30.

21. Nordestgaard BG. Triglyceride-rich lipoproteins and atherosclerotic cardiovascular disease: new insights from epidemiology, genetics, and biology. Circ Res. 2016;118: 547-63.

22. Ference BA, Graham I, Tokgozoglu L, Catapano AL. Impact of lipids on cardiovascular health: JACC health promotion series. J Am Coll Cardiol. 2018;72:1141-56.

23. Krauss RM. Lipoprotein subfractions and cardiovascular disease risk. Curr Opin Lipidol. 2010;21:305-11.

24. Johansson L, Schmidt C. Increased apoB/apoA-I ratio is predictive of peripheral arterial disease in initially healthy 58year-old men during 8.9 years of follow-up. Angiology. 2009;60:539-45.

25. Klarin D, Lynch J, Aragam K, Chaffin M, Assimes TL, et al. Genome-wide association study of peripheral artery disease in the Million Veteran Program. Nat Med. 2019;25:1274-9.

26. Gudbjartsson DF, Thorgeirsson G, Sulem P, Helgadottir A, Gylfason A, Saemundsdottir J, et al. Lipoprotein(a) concentration and risks of cardiovascular disease and diabetes. J Am Coll Cardiol. 2019;74:2982-94.

27. Joosten MM, Pai JK, Bertoia ML, Rimm EB, Spiegelman D, Mittleman MA, et al. Associations between conventional cardiovascular risk factors and risk of peripheral artery disease in men. JAMA. 2012;308:1660-7.

28. Criqui $\mathrm{MH}$, Aboyans $\mathrm{V}$. Epidemiology of peripheral artery disease. Circ Res. 2015;116:1509-26. 
29. Aday AW, Lawler PR, Cook NR, Ridker PM, Mora S, Pradhan AD. Lipoprotein particle profiles, standard lipids, and peripheral artery disease incidence. Circulation. 2018;138:2330-41.

30. Mach F, Baigent C, Catapano AL, Koskinas KC, Casula M, Badimon L, et al. 2019 ESC/EAS Guidelines for the management of dyslipidaemias: lipid modification to reduce cardiovascular risk. Eur Heart J. 2020;41:111-88.

31. Annemans L, Packard CJ, Briggs A, Ray KK. "Highest riskhighest benefit" strategy: a pragmatic, cost-effective approach to targeting use of PCSK9 inhibitor therapies. Eur Heart J. 2018;39:2546-50.

32. McDermott MM, Mandapat AL, Moates A, Albay M, Chiou E, Celic L, et al. Knowledge and attitudes regarding cardiovascular disease risk and prevention in patients with coronary or peripheral arterial disease. Arch Intern Med. 2003;163:2157-62.

33. Dopheide JF, Papac L, Schindewolf M, Baumgartner I, Drexel $H$. Poor attainment of lipid targets in patients with symptomatic peripheral artery disease. J Clin Lipidol. 2018;12:711-7.

34. Kuiper JG, Sanchez RJ, Houben E, Heintjes EM, Penning-van Beest FJA, Khan I, et al. Use of lipid-modifying therapy and LDL-C goal attainment in a high-cardiovascular-risk population in the Netherlands. Clin Ther. 2017;39:819-27.e1.

35. Teramoto T, Uno K, Miyoshi I, Khan I, Gorcyca K, Sanchez RJ, et al. Low-density lipoprotein cholesterol levels and lipidmodifying therapy prescription patterns in the real world: An analysis of more than 33,000 high cardiovascular risk patients in Japan. Atherosclerosis. 2016;251:248-54.

36. Aung PP, Maxwell H, Jepson RG, Price J, Leng GC. Lipidlowering for peripheral arterial disease of the lower limb. Cochrane Database Syst Rev. 2007.

37. Gerhard-Herman MD, Gornik HL, Barrett C, Barshes NR, Corriere MA, Drachman DE, et al. 2016 AHA/ACC Guideline on the Management of Patients With Lower Extremity Peripheral Artery Disease: Executive Summary: A Report of the American College of Cardiology/American Heart Association Task Force on Clinical Practice Guidelines. Circulation. 2017;135: e686-725.

38. Aboyans V, Ricco JB, Bartelink MEL, Björck M, Brodmann M, Cohnert T, et al. ESC Guidelines on the Diagnosis and Treatment of Peripheral Arterial Diseases, in collaboration with the European Society for Vascular Surgery (ESVS): Document covering atherosclerotic disease of extracranial carotid and vertebral, mesenteric, renal, upper and lower extremity arteriesEndorsed by: the European Stroke Organization (ESO)The Task Force for the Diagnosis and Treatment of Peripheral Arterial Diseases of the European Society of Cardiology (ESC) and of the 2017 European Society for Vascular Surgery (ESVS). Eur Heart J. 2018;39:763-816.

39. Pastori D, Farcomeni A, Milanese A, Del Sole F, Menichelli D, Hiatt WR, et al. Statins and major adverse limb events in patients with peripheral artery disease: a systematic review and meta-analysis. Thromb Haemost. 2020;120:866-75.

40. Kokkinidis DG, Arfaras-Melainis A, Giannopoulos S, Katsaros I, Jawaid O, Jonnalagadda AK, et al. Statin therapy for reduction of cardiovascular and limb-related events in critical limb ischemia: A systematic review and meta-analysis. Vasc Med. 2020;25:106-17.

41. Castaño G, Más R, Fernández L, Gámez R, Illnait J. Effects of policosanol and lovastatin in patients with intermittent claudication: a double-blind comparative pilot study. Angiology. 2003;54:25-38.

42. Mohler ER, Hiatt WR, Creager MA. Cholesterol reduction with atorvastatin improves walking distance in patients with peripheral arterial disease. Circulation. 2003;108:1481-6.

43. Heart Protection Study Collaborative Group, Emberson JR, Ng LL, Armitage J, Bowman L, Parish S, et al. N-terminal Pro-Btype natriuretic peptide, vascular disease risk, and cholesterol reduction among 20,536 patients in the MRC/BHF heart protection study. J Am Coll Cardiol. 2007;49:311-9.

44. Ramos R, García-Gil M, Comas-Cufí M, Quesada M, Marrugat J, Elosua R, et al. Statins for prevention of cardiovascular events in a low-risk population with low ankle brachial index. J Am Coll Cardiol. 2016;67:630-40.

45. Aronow WS, Nayak D, Woodworth S, Ahn C. Effect of simvastatin versus placebo on treadmill exercise time until the onset of intermittent claudication in older patients with peripheral arterial disease at six months and at one year after treatment. Am J Cardiol. 2003;92:711-2.

46. Kuritz SJ, Landis JR, Koch GG. A general overview of MantelHaenszel methods: applications and recent developments. Annu Rev Public Health. 1988;9:123-60.

47. DerSimonian R, Laird N. Meta-analysis in clinical trials. Control Clin Trials. 1986;7:177-88.

48. Pedersen TR, Kjekshus J, Pyorala K, et al. Effect of simvastatin on ischemic signs and symptoms in the Scandinavian simvastatin survival study (4S). Am J Cardiol. 1998;81:333-5.

49. Weir-McCall JR, White RD, Ramkumar PG, Gandy SJ, Khan F, Belch JJF, et al. Follow-up of atheroma burden with sequential whole body contrast enhanced MR angiography: a feasibility study. Int J Cardiovasc Imaging. 2016;32:825-32.

50. Momsen AH, Jensen MB, Norager CB, Madsen MR, Vestersgaard-Andersen T, Lindholt JS. Drug therapy for improving walking distance in intermittent claudication: a systematic review and meta-analysis of robust randomised controlled studies. Eur J Vasc Endovasc Surg. 2009;38:463-74.

51. Bregar U, Poredos P, Sabovic M, Jug B, Sebestjen M. The influence of atorvastatin on walking performance in peripheral arterial disease. VASA. 2009;38:155-9.

52. Mondillo S, Ballo P, Barbati R, Guerrini F, Ammaturo T, Agricola $E$, et al. Effects of simvastatin on walking performance and symptoms of intermittent claudication in hypercholesterolemic patients with peripheral vascular disease. Am J Med. 2003;114:359-64.

53. Cannon CP, Blazing MA, Giugliano RP, McCagg A, White JA, Theroux P, et al. Ezetimibe added to statin therapy after acute coronary syndromes. N Engl J Med. 2015;372:2387-97.

54. Bonaca MP, Gutierrez JA, Cannon C, Giugliano R, Blazing M, Park J-G, et al. Polyvascular disease, type 2 diabetes, and long-term vascular risk: a secondary analysis of the IMPROVEIT trial. Lancet Diabetes Endocrinol. 2018;6:934-43.

55. Sabatine MS, Giugliano RP, Keech AC, Honarpour N, Wiviott SD, Murphy SA, et al. Evolocumab and clinical outcomes in patients with cardiovascular disease. N Engl J Med. 2017;376:1713-22.

56. Schwartz GG, Steg PG, Szarek M, Bhatt DL, Bittner VA, Diaz R, et al. Alirocumab and cardiovascular outcomes after acute coronary syndrome. N Engl J Med. 2018;379:2097-107.

57. Bonaca MP, Nault P, Giugliano RP, Keech AC, Pineda AL, Kanevsky E, et al. Low-density lipoprotein cholesterol lowering with evolocumab and outcomes in patients with peripheral artery disease: insights from the FOURIER trial (Further Cardiovascular Outcomes Research With PCSK9 Inhibition in Subjects With Elevated Risk). Circulation. 2018;137:338-50.

58. Jukema JW, Szarek M, Zijlstra LE, de Silva HA, Bhatt DL, Bittner VA, et al. Alirocumab in patients with polyvascular disease and recent acute coronary syndrome: ODYSSEY OUTCOMES trial. J Am Coll Cardiol. 2019;74:1167-76.

59. Schwartz GG, Steg PG, Szarek M, Bittner VA, Diaz R, Goodman SG, et al. Peripheral artery disease and venous thromboembolic events after acute coronary syndrome: role of lipoprotein(a) and modification by alirocumab: prespecified analysis of the ODYSSEY OUTCOMES randomized clinical trial. Circulation. 2020;141:1608-17.

60. Ward NC, Watts GF, Eckel RH. Statin toxicity. Circ Res. 2019;124:328-50.

61. Stroes ES, Thompson PD, Corsini A, Vladutiu GD, Raal FJ, Ray KK, et al. Statin-associated muscle symptoms: impact on statin therapy - European Atherosclerosis Society Consensus Panel Statement on Assessment, Aetiology and Management. Eur Heart J. 2015;36:1012-22.

62. Parker BA, Capizzi JA, Grimaldi AS, Clarkson PM, Cole SM, Keadle J, et al. Effect of statins on skeletal muscle function. Circulation. 2013;127:96-103. 
63. Bruckert E, Hayem G, Dejager S, Yau C, Bégaud B. Mild to moderate muscular symptoms with high-dosage statin therapy in hyperlipidemic patients - the PRIMO study. Cardiovasc Drugs Ther. 2005;19:403-14.

64. Lotteau S, Ivarsson N, Yang Z, Restagno D, Colyer J, Hopkins $P$, et al. A mechanism for statin-induced susceptibility to myopathy. JACC Basic Transl Sci. 2019;4:509-23.

65. Cohen JD, Brinton EA, Ito MK, Jacobson TA. Understanding Statin Use in America and Gaps in Patient Education (USAGE): an internet-based survey of 10,138 current and former statin users. J Clin Lipidol. 2012;6:208-15.

66. Chowdhury R, Khan H, Heydon E, Shroufi A, Fahimi S, Moore $\mathrm{C}$, et al. Adherence to cardiovascular therapy: a meta-analysis of prevalence and clinical consequences. Eur Heart J. 2013:34:2940-8.

67. Zhang H, Plutzky J, Skentzos S, Morrison F, Mar P, Shubina $\mathrm{M}$, et al. Discontinuation of statins in routine care settings: a cohort study. Ann Intern Med. 2013;158:526-34.

68. Narula N, Dannenberg AJ, Olin JW, Bhatt DL, Johnson KW, Nadkarni G, et al. Pathology of peripheral artery disease in patients with critical limb ischemia. J Am Coll Cardiol. 2018;72:2152-63.

69. Eikelboom JW, Connolly SJ, Bosch J, Dagenais GR, Hart RG, Shestakovska O, et al. Rivaroxaban with or without aspirin in stable cardiovascular disease. N Engl J Med. 2017;377: 1319-30.

70. Berger JS, Krantz MJ, Kittelson JM, Hiatt WR. Aspirin for the prevention of cardiovascular events in patients with peripheral artery disease: a meta-analysis of randomized trials. JAMA. 2009;301:1909-19.

71. Bonaca MP, Scirica BM, Creager MA, Olin J, Bounameaux H, Dellborg M, et al. Vorapaxar in patients with peripheral artery disease: results from TRA2 P-TIMI 50. Circulation. 2013;127:1522-9.9e1-6.

72. Antithrombotic Trialists' Collaboration. Collaborative metaanalysis of randomised trials of antiplatelet therapy for prevention of death, myocardial infarction, and stroke in high risk patients. BMJ. 2002;324:71-86.

73. Caprie Steering Committee. A randomised, blinded, trial of clopidogrel versus aspirin in patients at risk of ischaemic events (CAPRIE). CAPRIE Steering Committee. Lancet. 1996; 348:1329-39.

74. Cacoub PP, Bhatt DL, Steg PG, Topol EJ, Creager MA. Patients with peripheral arterial disease in the CHARISMA trial. Eur Heart J. 2009;30:192-201

75. Belch JJ, Dormandy J, CASPAR Writing Committee, Biasi GM, Cairols M, Diehm C, et al. Results of the randomized, placebocontrolled clopidogrel and acetylsalicylic acid in bypass surgery for peripheral arterial disease (CASPAR) trial. J Vasc Surg. 2010;52:825-33.e1-2

76. Franzone A, Piccolo R, Gargiulo G, Ariotti S, Marino M, Santucci A, et al. Prolonged vs short duration of dual antiplatelet therapy after percutaneous coronary intervention in patients with or without peripheral arterial disease: a subgroup analysis of the PRODIGY randomized clinical trial. JAMA Cardiol. 2016;1:795-803.

77. Bonaca MP, Bhatt DL, Storey RF, Steg PG, Cohen M, Kuder $J$, et al. Ticagrelor for prevention of ischemic events after myocardial infarction in patients with peripheral artery disease. J Am Coll Cardiol. 2016:67:2719-28.

78. Anand SS, Bosch J, Eikelboom JW, Connolly SJ, Diaz R, Widimsky $P$, et al. Rivaroxaban with or without aspirin in patients with stable peripheral or carotid artery disease: an international, randomised, double-blind, placebo-controlled trial. Lancet. 2018;391:219-29.

79. Anand SS, Bosch J, Eikelboom JW, Connolly SJ, Diaz R, Widimsky P, et al. Major adverse limb events and mortality in patients with peripheral artery disease: the COMPASS trial. J Am Coll Cardiol. 2018;71:2306-15.

80. Bonaca MP, Bauersachs RM, Anand SS, Debus ES, Nehler $M R$, Patel MR, et al. Rivaroxaban in peripheral artery disease after revascularization. N Engl J Med. 2020;382:1994-2004.

\section{History}

Submitted: 24.06.2020

Accepted: 07.07.2021

Published online: 08.11.2021

\section{Conflict of interest}

$\mathrm{CB}, \mathrm{IB}$, PPoredos none.

JJFB sits on the PAD Advisory Board of Bayer.

$\mathrm{MB}$ is a consultant for Biotronic, Cook Ltd and Boston cientific. ALC participates in the speaker bureau for Akcea, Amgen, Sanofi, Esperion, Kowa, Novartis, Ionis Pharmaceuticals, Mylan, Menarini, Merck, Recordati, Regeneron, Daiichi Sankyo, Astrazeneca,

Aegerion, Amryt, Sandoz. He is a consultant on advisory boards for Akcea, Amgen, Sanofi, Esperion, Kowa, Novartis, Ionis Pharmaceuticals, Mylan, Menarini, Merck, Recordati, Regeneron Daiichi Sankyo, Genzyme, Aegerion, Sandoz. The work of ALC at MultiMedica been supported by Ministry of Health - Ricerca Corrente - IRCCS MultiMedica.

$\mathrm{CH}$ has published with Mars, and the Cranberry Institute. PParini has equity interests in Galmed Pharmaceuticals; has ownership in Lipoprotein Research Stockholm AB; has ownership of patent Japanese Patent No. 2020-011068; is member of the Scientific Advisory Board of Ambys Medicine and of Diaccurate SAS.

LT is Company consultant for Abbott, Amgen, Bayer, MSD, Mylan, Novartis, Sanofi and has participated in a study for Amgen.

\section{Editorial note}

This review is a joint publication of Vasa and Atherosclerosis.

\section{Funding}

JJFB receives speaker honoraria from Amgen, receives speaker honoraria from Bayer, receives funding from Regeneron for the adjudication committee of a clinical trial, and as PI of a second clinical trial. She receives funding from Daiichi Sankyo and Astra Zeneca for advisory Boards. MB received a speaker honorarium from BD Brad, Phillips, Medtronic, Bayer. ALC receives research grant/research support from Sanofi, Sanofi Regeneron, Amgen, Mylan, Menarini, Eli Lilly. TK has research grants to the Karolinska Institute from Amgen, Medtronic, and ReCor Medical, all outside the area of the work presented here. PParini received research grants from Amgen $A B$ and $A k c e a . ~ L T$ received company speaker honorarium from Abbott, Actelion, Amgen, Bayer, Daiichi Sankyo, MSD, Mylan, Novartis, Novo Nordisk, Sanofi, Servier, Pfizer, Recordati Abdi-ibrahim.

\section{ORCID}

Professor Jill Belch

(D) https://orcid.org/0000-0001-8280-6689

\section{Correspondence address}

Prof. Jill J. F. Belch for the ESVM

The Institute of Cardiovascular Research

University of Dundee

Ninewells Hospital and Medical School

Dundee DD1 9SY

UK

j.j.f.belch@dundee.ac.uk

\section{Correspondence address}

Lale Tokgözoğlu for the EAS

Department of Cardiology

Hacettepe University Faculty of Medicine 06230 Ankara

Turkey 